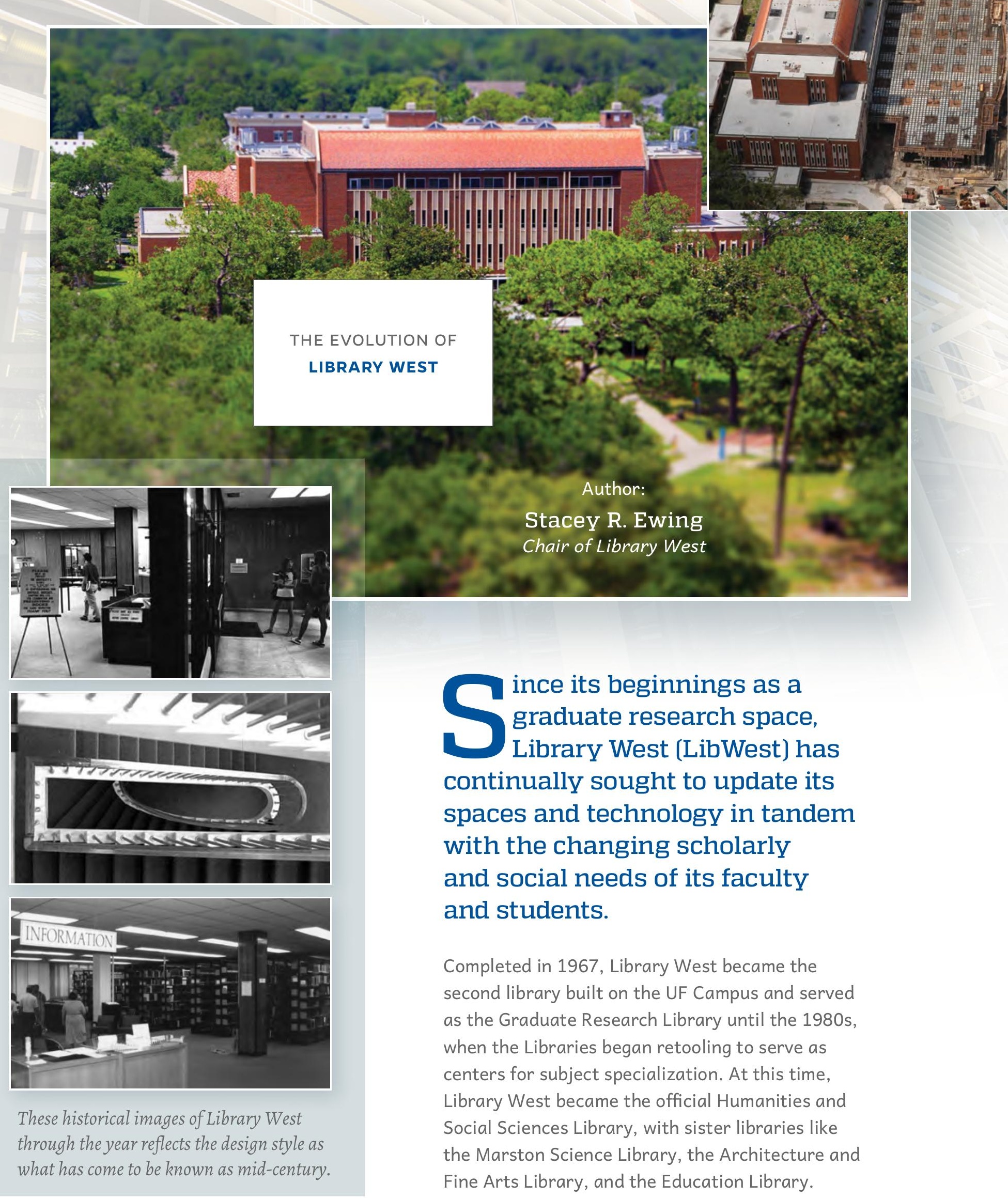


Fig. 3 2004, the addition of the north wing of Library West added 55,000 sq. ft., increasing the branches total by about $67 \%$.

In the 1990s, both the university's academic programs and its student enrollment expanded considerably, and Library West's collections were likewise extended to support this growth. This change, however, presented the branch with its first major growing pain, as it simply was not built to house a collection of that size while also providing sufficient spaces for students and faculty to study and conduct research. During this period, the branch underwent several

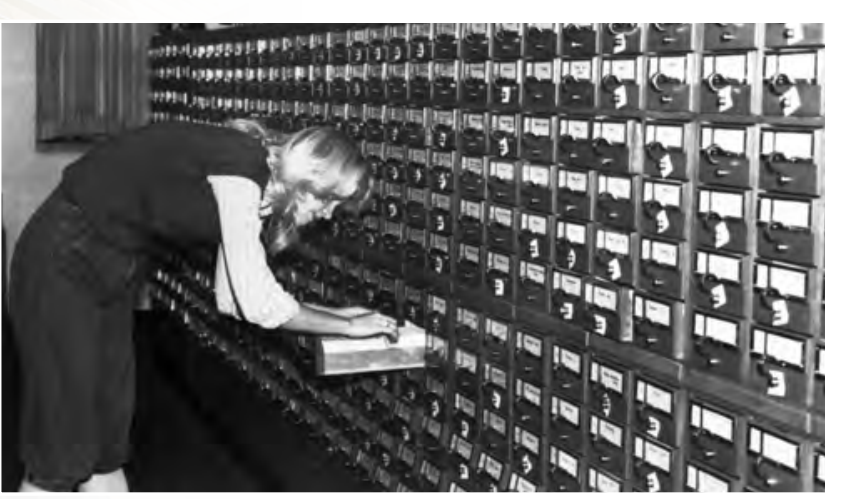
small but significant renovation projects. Its card catalog cabinets (Fig. 1) were removed and replaced by an Online Public Access Catalog, freeing up a Fig. I sizeable amount of room for study space. Renovations to staff areas facilitated workflow, and the transfer of materials to offsite storage and the reorganization of onsite collections liberated more room.

Near the end of the 1990s, Library West saw an increase in the number of specialized database computers and networked workstations-eighty computers in all-which became known as the "InfoSwamp." At this time, increased traffic from UF's ever expanding student population and the changing service expectations of its research community led to the closing of the branch in 2004 for a two-year, massive renovation that included the construction of a north wing.

This addition expanded LibWest's existing footprint from 50,000 square feet to 89,000 square feet, allocating even more collection space, which now boasted forty miles of track for movable shelving (Fig. 2), allowing the library to house 1.7 million volumes of print materials.

\section{Kisling Timeline:}

George A. Smathers Libraries' history was compiled by Vernon N. Kisling, Jr. through 2007. Vernon worked at the Smathers Libraries for more than 25 years, serving as the collection manager for the environmental sciences and the history of science. He also served as the Chair of the Marston Science Library.

\section{7}

The Graduate Research Library opened and the old library was designated the College Library. The names were changed to Library West and Library East in 1970.

\section{7}

Library East was renamed Smathers Library after Senator George A.

Smathers provided a significant gift to renovate the building. The renovations were completed in 1996.

Check out the entire Kisling Timeline: https://communications.uflib.ufl.edu/ at-a-glance/smathers-library-history.

\section{3}

Neuharth (founded USA Today) Reading Room relocated to Library West, Previously located

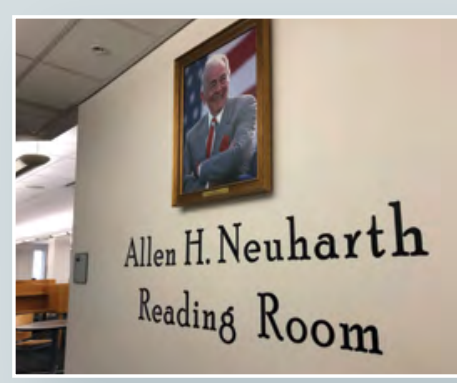
in Weimer Hall.

The mission is to serve the instructional and research needs of UF's College of Journalism and Communications. 


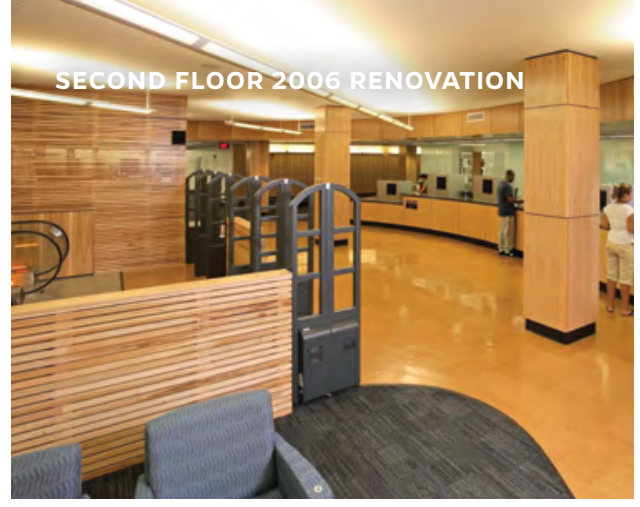

meeting, and project creation space for researchers in the digital humanities. Through a partnership with the UF Office of Academic Support, and the UF Writing Studio, free

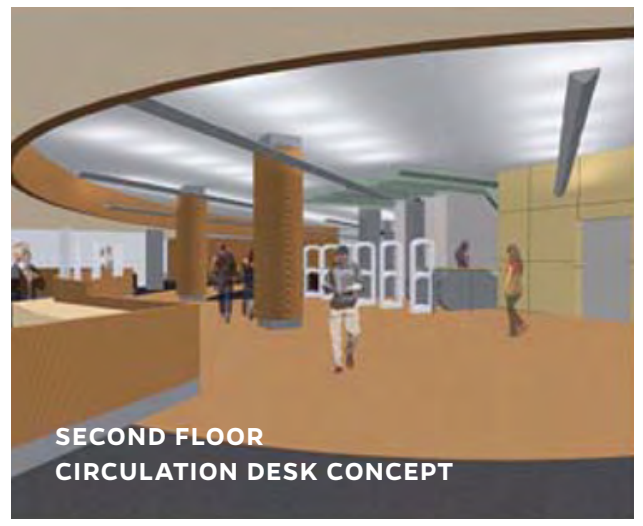
tutoring is available in the LibWest Tutoring Center. More recently, West's instruction classroom enjoyed a full renovation, transforming from a cramped classroom space, into the Library Instruction Lab.

Library West also continues to upgrade and improve technology offerings. Since 2009, hundreds of power outlets have been added throughout the building to accommodate mobile device users. Approximately six years ago, UF Academic Technology (AT) became a partner when it assumed management of all computers, software, printing, and study room A/V equipment within all the branches. Library West greatly benefited from this partnership, seeing the number of patron workstations increase to over 200 along with six new iMacs. AT also supports ten online proctoring booths in West, where students can take exams while being monitored remotely. With grant funding obtained by librarians from the UF Student Technology Fee Grants program, Library West has also provided students with upgraded group study room technology, a One Button Video Recording Studio, and high-speed digital scanners.
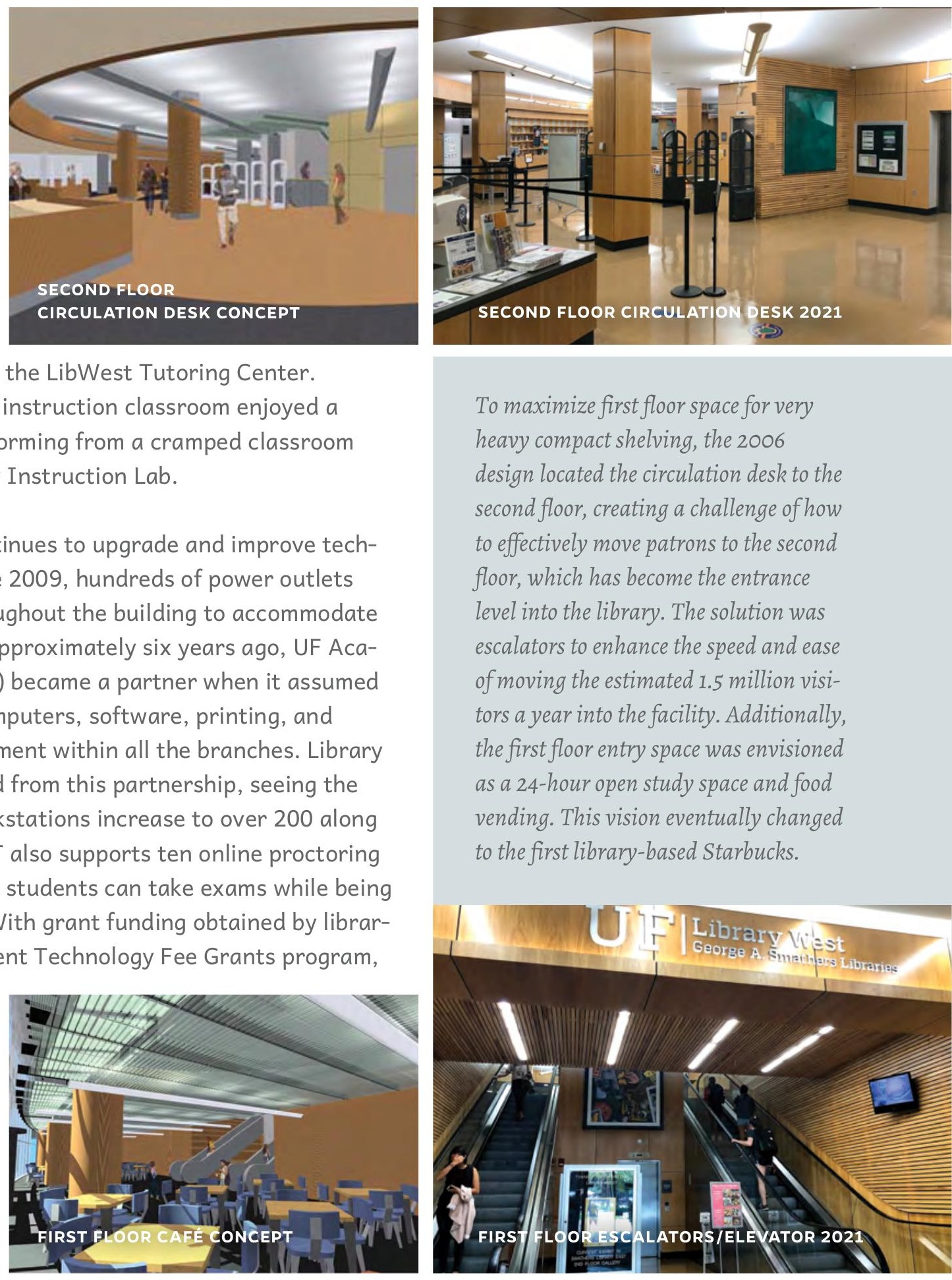

To maximize first floor space for very heavy compact shelving, the 2006 design located the circulation desk to the second floor, creating a challenge of how to effectively move patrons to the second floor, which has become the entrance level into the library. The solution was escalators to enhance the speed and ease of moving the estimated 1.5 million visitors a year into the facility. Additionally, the first floor entry space was envisioned as a 24-hour open study space and food vending. This vision eventually changed to the first library-based Starbucks.

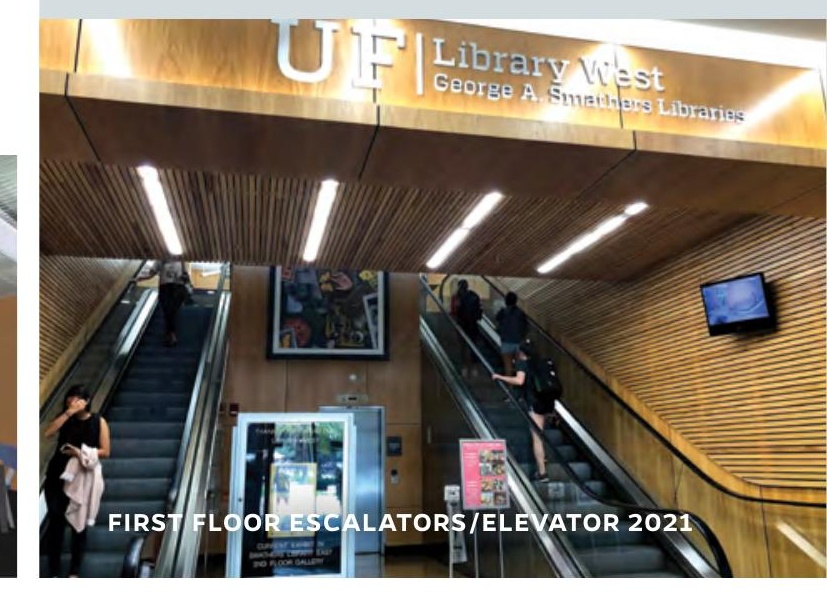


